\title{
Evidence and harm: time for reflection
}

\author{
David V. McQueen
}

Published online: 5 January 2014

(C) Swiss School of Public Health 2014

The three authors of the paper A scoping review of unintended harm associated with public health interventions: Towards a typology and an understanding of underlying factors in this issue (Allen-Scott et al. 2014) have provided an extremely useful and insightful service to those in public health who are concerned with the effect of public health interventions on populations. All too often, practitioners of public health have been more concerned with the evidence of effectiveness of interventions than with the potential adverse effect of the interventions (Fuller and Potvin 2012; Kelly and Moore 2012). This is hardly surprising because the scientific training of most practitioners and researchers in public health is designed chiefly to assess the effectiveness of the intervention itself (McQueen and Jones 2007). Assessing effect is the gold standard of institutional efforts such as those of Cochrane (1972), the Community Guide and many other such efforts (Briss et al. 2000; NICE 2008, 2009). It is also a common expectation of individual research efforts (Simoes et al. 2012, Jackson and Dickinson 2011). However, in almost all cases, the rigor expected of scientific research far exceeds the reality of what is obtainable in complex population based interventions. In reality, most public health interventions are messy, multivariate, loaded with possibilities for error and thus a major underlying problem of such efforts is the common finding of insufficient evidence of effectiveness. While this may not be such a startling outcome for one trained in the social sciences, it is often puzzling for those expecting the rigor of the vaunted

D. V. McQueen $(\bowtie)$

Global Consultant, 2418 Midvale Court, Tucker,

GA 30084, USA

e-mail: davidmcqueen07@gmail.com
RCT. As I have discussed elsewhere there are no simple, quick, or easy solutions to this common outcome (McQueen 2013). There are radical approaches, one could simply only report evidence that is sufficient, a rather draconian measure and ethically questionable. A "softer" solution is to report in depth why evidence could not be found and offer strategies for resolving the situation to arrive at an appropriate 'better' answer. Another option that suggests the precautionary principle is to make it clear that there is no evidence that any harm has been done by carrying out the interventions with insufficient evidence and continue to explore the area of insufficient evidence. Clearly, another alternative is to make use of the typologies suggested by AllenScott, Hatfield and McIntyre (2014).

The typologies suggested are worthy of pursuit. In my opinion, there are two areas that are particularly relevant for NCD and health promotion interventions, namely the cultural and environmental. However, these both pertain to the socio-political world in which most public health interventions operate. Throughout history, wealthier more powerful nations and peoples have exploited the poorer less powerful; this is hardly a revelation. However, many in the field of public health believe that they are exempt from such exploitation and operate at a level of higher cause and seek only to do well. This naiveté of action by the well intentioned argues strongly for the consideration of harm as a component of the design and implementation of every research project and/or intervention in public health and health promotion. In particular, this should be a common factor of all research that stems from the highly developed world when it is applied to the less developed. This is not simply a question of ethics, but an essential part of the issue of social justice. 
Allen-Scott et al. (2014) have presented many useful arguments for the incorporation of harm typology into public health interventions. Hopefully this is just the beginning of a fruitful discussion leading to further exploration of their suggestions and further in-depth examinations of the conduct of public health intervention research. The implications are for a review of the whole method and way in which evidence of effectiveness is sought. Clearly, current approaches do not address this deficit in understanding harmfulness. Other approaches of assessing effectiveness have been offered especially by many working in health promotion, efforts particularly from those using community-based approaches (Allison and Rootman 1996; McQueen and Jones 2007; Raine et al. 2010; Barczyk et al. 2010). However, there is a seeming reluctance of the biomedical-theoretically based community to accept or endorse such potentially appropriate efforts at assessment of effect. This, despite the fact that many such efforts start with a value-based, implied harm reduction basis for action with the focus on the community rather than on the effect of the research. It is now the time for reflexive thinking about the nature of our interventions and the associated research and in particular to consider with all seriousness the notion of harm in its broadest context.

\section{References}

Allen-Scott LK, Hatfield JM, McIntyre L (2014) A scoping review of unintended harm associated with public health interventions: towards a typology and an understanding of underlying factors. Int J Public Health 59. doi:10.1007/s00038-013-0526-6.

Allison K, Rootman I (1996) Scientific rigor and community participation in health promotion research: are they compatible? Health Promot Int 11(4):333-340
Barczyk J, Garcia J, Casabona J (2010) The potential contribution of small-scale intervention projects in the field to the national health information system for HIV and sexually transmitted infections: a case study of a multilevel intervention in Guatemala. Int J Public Health 55:693-699. doi:10.1007/s00038-0100179-7

Briss PA, Zaza S, Pappaioanou M, Fielding J, Wright-De Agüero L et al (2000) Developing an evidence-based Guide to Community Preventive Services-Methods. Am J Prev Med 18(Suppl 1):35-43

Cochrane AL (1972) Effectiveness and efficiency: random reflections on health services. British Medical Journal/Nuffield Provincial Hospitals Trust, London

Fuller D, Potvin L (2012) Context by treatment interactions as the primary object of study in cluster randomized controlled trials of population health interventions. Int J Public Health 57:633-636. doi:10.1007/s00038-012-0357-x

Jackson C, Dickinson DM (2011) Anti-smoking parenting practices: recall by and effect on children's risk of smoking after 3 years. Int J Public Health 56:263-270. doi:10.1007/s00038-010-0227-3

Kelly MP, Moore TA (2012) The judgement process in evidencebased medicine and health technology assessment. Soc Theory Health 10:1-19

McQueen DV, Jones CM (eds) (2007) Global perspectives on health promotion effectiveness. Springer Science \& Business Media, New York

McQueen DV (2013) The nature of causality: beyond traditional evidence. In McQueen DV (ed.) Global handbook on noncommunicable diseases and health promotion, Chp. 3. Springer, New York, pp 37-49

NICE (2008) Social value judgements: principles for the development of NICE guidance, 2nd edn. NICE, London

NICE (2009) Methods for the development of NICE public health guidance, 2nd edn. NICE, London

Raine KD, Plotnikoff R, Nykiforuk C, Deegan H, Hemphill E, Storey K, Schopflocher D, Veugelers P, Wild TC, Ohinmaa A (2010) Reflections on community-based population health intervention and evaluation for obesity and chronic disease prevention: the Healthy Alberta Communities project. Int $\mathrm{J}$ Public Health 55:679-686. doi:10.1007/s00038-010-0187-7

Simoes E, Mariotti S, Rossi A, Heim A, Lobello F, Mokdad AH, Scafato E (2012) The Italian health surveillance (SiVeAS) prioritization approach. Int J Public Health 57:719-733. doi:10. 1007/s00038-012-0341-5 